\title{
The New Development Context in Morocco and Communication for Development
}

\author{
Abil Abdallah, Erramli Imane
}

\section{ABSTRACT}

If development can be compared to the weaving of a cloth by millions of human beings, the thread of communication can weave the fabric in a sustainable way. And as long as the populations concerned by community development projects do not become the true actors of their own development management, no management or technology contribution alone will be able to improve their living standards in a sustainable manner. The contribution of communication to a development project is considerable: identification and prioritization of development priorities, search for collective solutions and reinforcement of the feeling of belonging to the said projects that they have decided to undertake. However, since the launch of the national incentive for human development in 2005, by His Majesty Mohamed VI, a multiplication of community development projects has emerged, aiming at the appropriation of communication strategies for development. However, due to a lack of professionalism, most LDAs are locked into rigid management logics exacerbated by the reference frameworks of international institutions. As a result, LDAs neglect the communication dimension of the development project to focus solely on its technical aspects.

Keywords: Communication for development, community media, communication strategy, development approach, mass media.
Published Online: December 7, 2021

ISSN: $2736-660 \mathrm{X}$

DOI:

10.24018/ejdevelop.2021.1.4.51

A. Abdallah*

ENCG Agadir, Morocco.

(e-mail: abilabilprofil@gmail.com)

I. Erramli

ENCG Agadir, Morocco.

(e-mail: erramli92@gmail.com)

*Corresponding Author

\section{INTRODUCTION}

Communication has always served as a tool for the management of companies. Today, it is resolutely put at the service of development. Indeed, communication is increasingly associated with development to constitute a specialized field requiring significant skills and resources, namely: communication for development. In the eyes of development specialists, it is the second most important factor in development after the human factor. The question is how to make it a real tool for development? How can it be effectively integrated into the various community development programs and projects in order to obtain appreciable results with a very positive impact on the populations concerned by the development project?

This article aims to address the different approaches in development in the current context of development in Morocco. It will also address the difficulties of using mass communication media and traditional or community communication media. First, we will present a review of the literature concerning, on the one hand, the definitions and concepts used in development. On the other hand, an idea on the evolution of approaches and methods in community development in the new context of development in Morocco. Secondly, we will discuss the place of mass communication media and traditional or community communication media for development in community development projects through the experiences of the local development associations (LDAs) of Souss-Massa.

Our research with LDAs in the Souss-Massa region revealed that the communicative dimensions of development are often neglected in the managerial approach of project planners, either because of rigid managerial logics or due to a lack of understanding of the contribution of communication to development on the part of actors and partners in community development projects.

\section{Literature Review: Concepts of Use AND APPROACHeS to DeVElopMent}

In Morocco, development has become the scene of major changes: the national human development initiative, new information and communication technologies that are becoming widely available, and institutional partners that are more willing to engage in new development partnerships. At the same time, the Moroccan economy seemed to be experiencing the first effects of the international crisis in recent years. Morocco, given the progress made in macroeconomic consolidation, was able to respond quickly to this 
crisis, allowing the Moroccan economy to be better prepared for the post-crisis environment. The crisis has revealed the urgent need to address the following structural deficiencies:

- Poverty is on the rise, creating intolerable economic and social situations;

- International financing institutions are imposing strict obligations on local governments to reduce public spending;

- Population growth and its pressure on basic services and jobs.

- The efforts undertaken and the progress made against poverty, the social development indices still demonstrate the complexity for the Moroccan economy to transform growth into social and human well-being for a large part of the Moroccan population.

We will now present a review of the literature concerning the definitions, concepts of use concerning "development" and an idea on the evolution of the approaches and methods of development in the new context of development in Morocco. However, we will only focus on the communication for development and community development approach.

\section{A. The Concept of Development: Definition and Origin}

According to the Treasury of the French Language" (TLF), the word development refers to: "the action of developing, improving or the result of this action". The United Nations Development Program (UNDP, 2001) states that development aims to: "creating an environment in which people can develop their full potential and lead productive and creative lives". This view is supported by Ronald Legouté (2001), for whom development implies: "an increase in social welfare, changes in structures. It involves (...) urbanization, industrialization, literacy and training and produces at the confluence of this combination a more efficient system where human needs are better met".

The concept has nevertheless evolved and is now adapted to the changing socio-economic and political realities of societies. There are several reasons for this evolution: the ineffectiveness of projects undertaken in the 1990s to lift people out of poverty.

\section{B. Sustainable and Equitable Development}

The concept of sustainable development is of Anglo-Saxon origin. It appeared in 1987 with the report of Mrs. Brundtland, president of the World Commission on Environment and Development of the UN. According to this report, sustainable development: "meets the expectations of current generations to satisfy their needs without compromising the ability of future generations to satisfy theirs" (WCED, 1988). However, environmental problems will always be present and more threatening and people will have to face misery and injustice (Brundtland, 1987).

\section{Local and Regional Development}

Local development is a new approach based on partnership, mobilization and participation of local stakeholders. It aims to enhance the value of projects by local actors organized in partnership to create wealth. Regional development is a major development issue for Morocco, which aims to reduce socioeconomic disparities between its regions, by fighting against the center-periphery and city-country divide. The advanced regionalization project will enshrine the principle of solidarity between regions in order to help mitigate the effects of lagging development.

\section{Community Development}

The definitions of community development vary from one context to another. We find the terms: community development, community action, community organization, local social development, participatory development. André (2002) cited by Guay (2003) speaks of community development as: "a set of collective actions aimed at satisfying local interests of a socio-economic nature". According to him, community development leads to what he calls "social or alternative economy" which is a development project based on "collective management, the search for profitability without the objective of enrichment" but whose production responds to the real needs of the community. However, the experiences of the 1970s and 1980s led to very poor results, according to the mixed opinions of specialists in community development projects. These projects seem to be designed and implemented by experts and exclude any involvement of local actors. That said, they remain an effective way for marginalized communities to value their projects and space in the fight against poverty.

\section{The Evolution of Approaches to Development in Morocco: Limitations And Assets}

\section{A. The Integrated Territorial Approach to the Fight Against Poverty}

It contributes to a better synergy between local economic development and social development. It aims to improve the living conditions of disadvantaged people. It also constitutes the concrete anchoring on the ground of the national strategy to fight poverty and social exclusion. According to ANDRE, Joyal: "both 
territorial (anchored and adapted to a territory) and integrated (concerted. Intersectoral, multi-network and multi-level), centered on a sociological territory (in the sense of living environment), aims at local actors taking charge of the development of their community".

\section{B. The National Human Development Initiative (Nhdi) Approach}

On May 18, 2005, His Majesty King Mohammed VI delivered a historic speech in which he announced the launch of the National Initiative for Human Development (INDH). In his speech, His Majesty King Mohammed VI made the following observation: "Large sections of the Moroccan population live in very difficult conditions, sometimes even incompatible with a decent life. These populations, living in slums, poor urban and peri-urban areas, and in several rural communes, suffer from the absence of the most basic social services such as health, education, water, electricity, cultural infrastructures, etc." The Sovereign affirms that poverty cannot be eradicated only by punctual aid or spontaneous charity action or by an ethical duty, H.M. the King stressed in his speech. The Sovereign advocates sustainable development based on public policies integrated into a global project to which all components of society must adhere.

The National Initiative for Human Development is a comprehensive and integrated approach based on a territorial social development logic supported by a bottom-up approach of participation and planning in order to improve the standard of living and empower the poor in target communities. The NHDI has also supported the access of vulnerable groups to social and economic services provided by the State and nongovernmental organizations.

\section{The Institutional or Agency Approach}

It is the intermediation between the State and the civil society represented by the Agency of Social Development, the Agency of the Oriental and the Agency for the promotion and the economic and social development of the provinces of the South of the Kingdom whose principal mission is the valorization of the local initiatives of development by proposing them a technical and financial support.

\section{The Communication for Development Approach}

The concept of communication for development emerged in the context of the contribution of communication and the media to the development of Third World countries. According to Guy Bessette, "at the heart of this concept is the need for an exchange of information that contributes to solving a development problem and aims to improve the quality of life of a specific target group. The approach has been deployed for several years in the programs of the International Development Bank environment, the lack of efficiency in the use of the communication supports and media used is very real. Several reasons are given for this by development actors, namely:

- Lack of synergy between the communication strategies deployed by the LDAs, which regularly and independently intersect in the same geographical area and sometimes in the same sector of activity. Very often, the approaches prove to be antagonistic and lead to perverse effects.

- Lack of social anchorage of the actions: the approaches in development have sometimes been conceived outside the norms and referential.

- Let us now come to the last axis of this article, namely: the place of media for development in a new development context through two consulting experiences.

- Realization of a global communication plan of the Association Network of Associations of the "Arganeraie" biosphere on the place of communication in community development projects.

- Realization of a communication strategy on water saving within the framework of the SWIM-USAID (water integrated management) project (SWIM).

\section{The Place of the Media in Community Development Projects}

In all development projects, the place of communication is often situated at the level of the following three distinctive axes:

\section{A. Access to Project Information}

Information is an essential element for any development project. It must be available and easily accessible to all, whether it is scientific, technical, economic, administrative or other information. The role of the media is to make people aware of the usefulness of information and its contribution to improving the exchange between the various actors involved in the development project.

\section{B. Establishing A Dialogue between the Various Project Actors Involved}

In order to do this, the media must lead to a permanent dialogue between the different actors or partners of the project and to a better confrontation of their ideas and opposing options. The expression of ideas through organized debates on different development themes. The dialogue contributes to valuing traditions, 
customs and popular knowledge that are often ignored in communication approaches. Experience has shown that folk knowledge often provides simple, realistic and feasible solutions.

\section{Exchanges of Experience, Knowledge and Project Techniques}

The exchange of experiences, knowledge and techniques requires the communication officer to adapt to the multiplicity of actors involved, to master the desired development issues, and to mobilize the tools and networks of communication. development issues, and mobilize existing communication tools and networks. tools and networks. Each target group has specific expectations in terms of information, dialogue and exchange of experiences. Each target group has specific expectations in terms of information, dialogue and exchange of experiences. Hence the need to use communication media adapted to access project information, the establishment of dialogue between the various project actors and the exchange of experiences, knowledge and techniques of community development projects. Another constraint is that these media must be mobilized according to the development objectives pursued, taking into account their impact, the flexibility of use, the cost of implementation and the possibility for the populations concerned to appropriate their use. This is not always easy, at least on the theoretical level.

In what follows, we will talk about these constraints on the use of communication media in community development projects, more particularly according to the three axes of intervention mentioned earlier, namely: access to information, the establishment of a network of In what follows, we will discuss these constraints on the use of communication media in community development projects, more specifically according to the three axes of intervention mentioned earlier, namely: access to information, the establishment of a dialogue between the different project actors involved and the exchange of knowledge and techniques.

\section{The Different Media of Communication for Development in Ldas Subject of Our Research}

1. Mass communication media: Mass communication medica is still very common in community development projects because of illiteracy. Personally, I have learned in my facilitation work to pass on my technical knowledge to an uninformed audience through mass media. Some of these mass media include:

\section{a) Television}

Most programs devoted to development issues are still very rare in our country. However, there are some limited attempts by private channels. This mode of communication deserves to be better exploited to take advantage of the possibilities of this powerful tool of information, education and exchange of experiences through the broadcasting of television images.

\section{b) Radio}

Radio is the most appropriate means of mass communication for the rural world. In the villages, many homes have a radio receiver, which is often equipped with a cassette player/recorder. In Morocco, radio stations are now developing at the regional and local level. Taking into account the socio-economic and cultural particularities, they are able to satisfy the expectations of a large and varied public, to whom they address themselves in the various languages spoken by the populations. In order to be listened to by its audience, the radio has to meet their expectations: this requires a preliminary work of listening in order to collect the expectations of the populations and then to answer them in an adapted way in terms of information, exchange between populations concerned by the development project, dialogue with the decision-makers, entertainment and valorization of the heritage. That said, we note:

- The absence of mobile teams to travel to remote locations and present programs in dialogue with the population affected by the project,

- The lack of interdisciplinarity of the production teams in order to identify the subjects addressed, to appreciate local knowledge and traditional techniques.

\section{c) The slide language}

The SlideShare is a dialogue tool that is mainly used in awareness-raising and decision support activities. The SlideShare technique consists of projecting a series of slides describing various situations that are the object of the development project: saving water, preserving natural resources, etc. These images are used as a support for a facilitation session conducted with a group of populations concerned by the project. The slides are chosen from an image bank or, better still, are made in the area itself. They are generally rich in information. The design of the slides is a very delicate step. It requires a prior definition of the objectives and a great deal of skill in conducting debates.

The slide show is a tool that is particularly well suited to establishing dialogue between the various project stakeholders. It allows the technician-facilitator to encourage dialogue and the expression of the groups concerned. It also contributes to the emergence of solutions proposed and achievable by the populations. This being said, we note that with the Slide-Language technique:

- Project facilitators do not always adapt the tool to the development objectives being pursued;

- Projected slides do not always stimulate positive or negative reactions from people; 
- Project facilitators do not use their facilitation skills to encourage public speaking and sometimes comment on the images themselves in front of a mute or distracted audience,

- The absence of a perfect mastery of animation techniques by the project animators.

\section{d) Language or picture board}

The language board is a variant of the slide show and is intended for smaller groups of 12 to 15 people. It uses a graphic medium and not a photographic one. It consists of several large painted canvases $(0.80 \mathrm{~m}$ to $1.20 \mathrm{~m}$ ) created by a local artist. They describe situations of exploitation or degradation of the environment encountered in the agroecological zone. As with the SlideShare, these images serve as a starting point for a facilitation session that will encourage participants to speak out, reflect on the problem, identify solutions that can be implemented by the population, and identify the necessary support. It allows to present a technical problem in a synthetic and schematic way with drawn images, diagrams or graphs and is intended to encourage the expression of an audience on a given technical problem and illustrate the technical demonstration made by a technician by breaking down, for example, the steps of a technical process.

\section{e) Fixed film and slide show}

The fixed film or slide show is a series of slides on a particular theme. The fixed film is designed to:

- Encourage logical thinking,

- Intervenes directly as a support for awareness, information or training on a given technical theme,

Describes an activity carried out in the field by putting in scene real characters who carry out the

precise technical gestures corresponding to the activity of development whose learning is aimed,

- Constitutes an excellent didactic and auxiliary support for information, awareness or learning of technique.

\section{f) Video}

Video is an interesting medium because of its flexibility and rich moving images. Video is used to share testimonies, report on important events, and film development theater performances. The video tapes produced can be used as an element of animation in group discussions. That said, several constraints sometimes make its use difficult, such as the lack of video production centers to produce information or training materials.

\section{g) Image box}

Designed in the form of giant notepads, the picture box is an interesting support for an animation or training session. It allows to present a technical problem in a synthetic and schematic way with drawn pictures, diagrams or graphs and is intended to encourage the expression of an audience on a given technical problem and illustrate the technical demonstration made by a technician by breaking down, for example, the steps of a given technical process.

The picture box is used in combination with the slide show and the still film. The latter consists of a series of slides on a particular theme or didactic scenario. The still film is designed to encourage logical thinking. This communication medium, which is less interactive, differs from the slide show in that it is used directly as an awareness, information or training medium on a given technical subject. It illustrates or breaks down the different steps of a technical activity. It describes an activity carried out in the field by putting on stage real characters who carry out the precise gestures of the project corresponding to the activity whose learning is aimed at. The film generally alternates between general shots and close-ups, diagrams or graphics; it thus makes it possible to communicate a detailed description of the technical activity.

\section{Traditional or community communication media}

Traditional or community communication media is the second most important means of communication for development. They are numerous and varied. They are often the most effective way to inform, sensitize and mobilize the populations concerned by the development project. They differ from one region to another according to the historical, cultural, and religious context. They use two communication channels, namely:

\section{a) The socio-traditional channel}

It represents all community-based and ethnic-religious organizations such as: community leaders; association leaders and opinion leaders.

\section{b) The event channels}

It represents moments of mobilization and social awareness of information: socio-traditional festivals, informal popular gatherings, fairs, and other such gatherings. The main quality of traditional or community communication media is that they are interactive. As such, they stimulate the participation of the community's constituent groups in the decision-making process and the flow of information, channel social discontent through culturally acceptable forms of communication and contributes to consensus building among the interest groups involved in the development project. 
Given its importance and influence, we will focus on only one traditional or community communication medium, namely: theater for development. In Morocco the traditional forms practiced by the populations in underprivileged areas are:

- The lbsat,_a spectacular and satirical rite of the 18th century, close to the carnival processions. The Moroccan sovereigns of the last centuries were very interested in it because it was a kind of thermometer of the economic, political, social and cultural situation of the society.

The halqaou, street theater, for some; it is the cradle of theater. The audience forms a circle around the multi-talented artist who calls out to them and makes them participate.

Indeed, in the Moroccan context characterized by a low level of schooling in most of the regions concerned by community development, theater for development is a tool par excellence for communication and development. The latter often resorts to the artistic languages of the people: songs, dances, tales and uses a style of play where the word is oratory, where the play is performance. These elements often stimulate the critical sense, the pleasure, or the curiosity of the spectator. Theatrical play is intimately linked to: social organization, rituals, rites and traditional artistic expressions.

Theater for development" is a space where decision-makers and populations are subjected to critical scrutiny under the guise of humor, comedy, aesthetics, dreams, or derision. Unfortunately, it is under-used by development project planners for various reasons. Firstly, the concept is poorly mastered and the theatrical play does not always highlight the expectations, the objectives pursued by the development project and its operational mode. Secondly, the spectator is often content with a passive and mortified attitude in the face of the lack of understanding of the project's goals and the way it is carried out.

Whereas the "development theater" is a place of exchange where anyone can freely give their opinion, intervene on the scene, and commit themselves to the success of the development project. From this point of view, it is recognized that the development theater session is a moment of tonic expression where resignation and submission give way to the feeling that change is possible and that man is master of his destiny. Contrary to the usual theater, where theater is used to create social agitation and provoke the participation of the audience in the process of society, the "theater for development" consists in gradually bringing the whole community of the project to express itself through the theatrical language about the concerns of the community.

\section{CONCLUSION}

At the end of our reflection, we will say that communication for development is, in more than one way, at the heart of the problem of community development and that, as such, scientific and material investments will be ineffective if they are not accompanied by adapted communication mechanisms, so that the contributions of development projects are exploited in an optimal way. The establishment of a development communication system also implies the existence of competent and trained development communication agents; essentially on: the design, production, exploitation and dissemination of mass media and traditional or community media. In addition, knowledge of how to formulate and implement a community development communication strategy is essential. Development communication can make a significant contribution if the following conditions are met:

- The establishment of a communication framework that defines and harmonizes the standards and practices of development communication,

- The media is a key factor in the success of the communication for development approach, provided that the various development actors are proficient in the different media. The media are an essential factor for the success of the development communication approach, provided that the various development actors master the various media. Because development communication activities have various objectives (information, training, etc.) and are aimed at several types of actors (populations concerned by the development project, local management actors, NGOs, partners, etc.).

\section{ACKNOWLEDGMENT}

The researcher wants to thank all the participants for this study.

\section{REFERENCES}

Bessette, G, Rajasunderam, CV. (1977). Communication for Development in West and Central Africa: Towards an Intervention and Research Agenda. CRDI Publication, Ottawa.

Boucher, M. (2006). L'expérience de la Ville de Montréal: l'approche territoriale intégrée. Paper presented at the CACIS forum, Income Security and Social Development Branch, Montréal City.

Brundtland, H. (1987). The close link between poverty and environmental risks in the report of the World Commission on Environment and Development http://www.wikilivres.info/wiki/Rapport_Brundtland. 
Guay, L. (2003). André Joyal, Le développement local. Comment stimuler l'économie des régions en difficulté, Sainte-Foy, Les Éditions de l'IQRC, 2002, 156 p.(Diagnostic, 30.). Recherches sociographiques, 44(3), 590-593.French.

Legouté, J. R. (2001). Définir le développement: historique et dimensions d'un concept plurivoque. Économie politique internationale, Cahier de recherche, 1(1). French.

Legouté, J. R. (2001). Définir le développement: historique et dimensions d'un concept plurivoque. Université du Québec à Montréal, Groupe de recherche sur l'intégration continentale. French.

Rachid El Omari (2007) dans : «La structure organisationnelle du RARBA: Analyse et renforcement; Université Mohammed 5, Faculté des Sciences Juridiques, Économiques et Sociales, Salé - Licence professionnelle en développement local.

United Nations Development Program (UNDP), Human Development Report, 2001.

World Commission on Environment and Development (WCED), 1988. Our Common Future, Fleuve Editions /Quebec's publications, Montreal.

Reports:

Report on advanced regionalization/Book III: advanced regionalization for economic and social development. URL: http://www.regionalisationavancee.ma/PDF/Rapport/Fr/L3_Dev_Eco_So.pdf

Full historical speech delivered by His Majesty King Mohammed VI, available on the website of the Ministry of the Interior, Directorate of the INDH. Online : http://www.indh.ma/chantier-de-regne/ 